Resenha do livro:

BUNN, Maria Cristina. Rede como lugar de Potência: o CFEMEA e as Práticas Políticas Mediáticas. São Luiz: FAPEMA, 2012, 279p.

\title{
REDES REAIS E VIRTUAIS E AS POLÍTICAS DA VIDA
}

\section{Vera F. Gasparetto*}

O livro da Socióloga Maria Cristina Bunn é resultado da tese de Doutorado em sociologia, defendida na Universidade Federal do Ceará em 2004, na qual a autora pesquisou a utilização do ciberespaço ${ }^{1}$ pelo Centro Feminista de Estudos e Assessoria (CFEMEA) ${ }^{2}$. A autora reflete teoricamente sobre práticas e potencialidades dos movimentos sociais para a construção de direitos das mulheres em rede de modo a ampliar a cidadania e a democracia. Atualmente Bunn é vinculada à Universidade Federal do Maranhão e atua nos temas redes, hibridismos culturais, movimentos sociais, direitos humanos, cibercultura, sociologia da cultura, entre outros.

Entre as questões colocadas pela autora no decorrer de sete capítulos está a busca em compreender os significados e sentidos produzidos por uma cibercultura enquanto geradora de redes de movimentos e se o cenário da Internet, dito como interativo, cooperativo e descentralizado, cria uma nova arena política para os movimentos sociais na rede técnica com a possibilidade de difundir suas reivindicações, estratégias e formas de organização independente de tempo e espaço. Seu objetivo é entender como as redes de movimentos utilizam a Internet e qual o efeito destas sobre os processos políticos, as transformações culturais e a necessidade de pensar "políticas de subjetividade" (BUNN, 2012, p. 115).

A era da hipervelocidade reconfigura os campos da comunicação e da cultura, produzindo novas subjetividades e possibilidades não só no acesso e produção de informação, mas na forma de pensar, no processo cognitivo e em relações antagônicas com a máquina (hardware e software): "Se a hipermídia encarna para alguns o cenário sinistro de Matrix, onde

\footnotetext{
*Mestranda do PPGSP - UFSC. Contato: gasparettovera@yahoo.com.br

${ }^{1}$ Refere-se ao ambiente da Internet passível de ser caracterizado como tendencialmente interativo, cooperativo e descentralizado.

${ }^{2}$ Criada por um grupo de feministas em 1989 para buscar a regulamentação dos direitos da mulher aprovados na Constituição de 1988, com sede em Brasília-DF.
} 
seres humanos são dominados pela máquina, também traz consigo potencialidades que, para alguns, permitem identificá-la como Ágora do terceiro milênio" (BUNN, 2012, p. 36).

É importante lembrar que a autora realizou seu trabalho de campo no ano 2000, quando a utilização da Internet no Brasil era de baixo alcance no conjunto da sociedade e expressões e conceitos que ela utiliza na obra, característicos do ciberespaço e da hipermídia e atualmente comuns, não eram usuais, o que a levou a se deter na recuperação epistemológica de termos e tratar de maneira didática a utilização das palavras, fazendo uma espécie de glossário do mundo virtual relacionado aos movimentos sociais e à construção de direitos. De lá para cá houve um crescimento vertiginoso no tráfego global de dados na Internet de 284,86 vezes ${ }^{3}$.

Bunn utiliza a palavra Rede (do latim retis) que significa entrelaçamento de fios com aberturas regulares que formam uma espécie de tecido, e aplica o conceito ao tecido social, por ser uma alternativa prática para a compreensão da organização social contemporânea: "Redes são entendidas, então, para esse fim, como sistemas organizacionais capazes de reunir indivíduos e instituições de forma democrática e participativa, em torno de causas afins" (BUNN, 2012, p. 26). Com a adesão à rede (web) as entidades e ativistas entram num campo da comunicação que favorece relações horizontalizadas, onde emissores e receptores são usuários que recebem e produzem informação e interagem com outro parâmetro de espaço e em tempo real.

Bunn percorre caminhos teórico-metodológicos que revelam os esforços de elaboração de novas categorias de entendimento dos processos políticos causados pela revolução informacional (CASTELLS, 1999) e dialoga com vários autores a fundamentação teórica da pesquisa. Utiliza a concepção de potência no sentido formulado por Peter Pélbart como “potência política da vida" (2000; 2002; 2003), fundamentado em Foucault (biopoder) e Deleuze (biopolítica). A rede como uma estrutura rizomática, pois pode ser quebrada em algum lugar mas retoma suas linhas (DELEUZE-GUATTARI, 1995 apud BUNN, 2012, p. 23).

Baseia-se na categoria de cibercultura para a qual a virtualização deve ser entendida como "uma mutação de identidade, um deslocamento do centro de gravidade ontológico" (LÉVY, 1999 - grifo do autor) pelas confluências que cria entre os padrões clássicos de interação social e as redes eletrônicas. A Internet leva vantagem na comparação com outros meios de

\footnotetext{
${ }^{3}$ A criação da Internet foi em 1969 (EUA). Dados comparativos entre os anos 2000 e 2011 demonstram a evolução do tráfego de dados na internet em petabytes.
} 
comunicação de massa por romper com a chamada intermediação, que faz "filtro" entre o que deve ser noticiado, destacado, deturpado ou ocultado (CAIAFA, 2001). Analisa que a sociedade contemporânea presencia o "fim da geografia", onde acabam as fronteiras entre o local e o global, constituindo a chamada "cronopolítica" e a industrialização da percepção, sendo essas desencadeadas pelas novas tecnologias da imagem, que anunciam o fim de uma lógica da representação pública, pois a virtualidade perturba a noção de realidade e é substituída pela tele-presença (VIRILIO, 1999).

Essa sociedade em rede e a revolução tecnológica associam-se para Castells (1999b) à reestruturação do capitalismo em quatro dimensões: 1) globalização das atividades econômicas; 2) flexibilidade e instabilidade no emprego; 3) cultura da virtualidade; 4) transformações das bases materiais da vida, fluxos e tempo intemporal. Para compreender o impacto desse novo cenário Bunn alarga os conceitos, analisando mudanças teóricas e práticas para o estudo dos movimentos sociais do final do século XX.

A autora prioriza o recorte da teoria dos movimentos sociais que trata das abordagens de redes que remetem às categorias de análises relacionadas ao que chama de movimentos, redes e redes de movimentos. Até a década de 1970 a orientação teórica era de referência marxista e funcionalista. Esses paradigmas foram criticados a partir dos anos 1960, concomitante às mobilizações culturais que marcaram as novas teorias dos movimentos sociais (MORIN, 1980; ROSZAK, 1985; HELLER, 1987/88; GALTUNG, 1985), remetendo a novas abordagens que passaram a considerar o "mundo da cultura", a pluralidade dos atores coletivos e o cotidiano da vida em sociedade.

Aquelas novas tendências foram agrupadas em Teoria dos Novos Movimentos Sociais (TNMS), voltada à compreensão dos aspectos culturais; e Teoria da Mobilização dos Recursos (TMR), voltada para os aspectos institucionais. Mas outros esforços teóricos, desde meados dos anos de 1980, buscam uma síntese que integre ação e estrutura, bem como a ampliação e imbricação dos conceitos de cultura e política, para superar o que considera uma falsa dicotomia. Estes estudos trazem uma nova perspectiva para as análises de redes de modo a contribuir para o estudo dos movimentos sociais (SCHERER-WARREN, 1996). A partir dos anos 1990 passam a serem percebidas como redes de movimentos, que constituem o lócus e o modus em que se estruturam as ações sociais, e através delas, as interações entre indivíduos e grupos sociais, influências, negociações e motivação para a ação coletiva (MELUCCl, 2001 apud SCHERER-WARREN, 2002). 
Do processo de democratização da sociedade brasileira emergiram diferentes movimentos por direitos sociais, econômicos, políticos e culturais, que levaram a repensar a concepção, as práticas políticas e o conceito de sociedade civil para abarcar a complexidade do tecido social no cenário brasileiro, composto por diferentes atores caracterizados como hibridismos (p. 59). Nesse cenário investiga o potencial transformador da organização do movimento de mulheres em rede e através das redes e a pertinência dessas categorias para o estudo das organizações sociais.

A autora faz uma reflexão sobre as dificuldades de uma universalização categórica das teorias feministas apoiando-se em Butler (2003 - grifo nosso) para debater as instabilidades e polêmicas epistemológicas e ideológicas, utilizando como exemplo as discussões em torno do termo "identidade". Observa na pesquisa a predominância de um feminismo dos direitos que indica um refluxo das tendências socialista e radical e uma tendência de pluralização do feminismo devido às práticas contemporâneas na América Latina que levam à ruptura da fronteira entre feministas e não feminista, ampliando o número de protagonistas, a variedade de arenas e pautas. Essas mudanças impactaram as organizações não-governamentais (ONGs), que para Bunn (2012 - grifo da autora) se destacam devido ao trabalho de mediação e atuação junto a diferentes campos sociais e que contribuem com a formação de redes de movimentos.

É bom lembrar que um trabalho recente de Scherer-Warren (2012) amplia o debate ao considerar que a rede de movimento social é uma articulação de vários atores e pressupõem sujeitos coletivos em torno de valores, objetivos, projetos em comum ou utopia de mudança social. Indica que as políticas emancipatórias construídas pelas redes de movimentos na América Latina no final do século XX valorizam mais as formas de participação institucional e a oportunidade do exercício do controle social pela cidadania, constituindo espaços de governança que dialogam com concepções plurais de mundo, respeito às diferenças, defesa das causas dos excluídos com democracia e diversidade.

Para a pesquisa empírica sobre as práticas políticas mediáticas e a organização em rede e na rede a autora fez de um estudo de caso da ONG CFEMEA - referência nacional e internacional na defesa dos direitos das mulheres e que atua junto ao Congresso Nacional (Câmara dos Deputados e Senado Federal), articulando projetos de ampliação dos direitos e da cidadania, além de buscar o empoderamento do movimento de mulheres. 
Bunn observa que a imbricação dos eixos de atuação ${ }^{4}$ do CFEMEA resulta na organização na rede e em rede da ONG e no fator político do lugar das mulheres no espaço público e na construção de direitos por intermédio da cibermilitância. As redes sociais favorecem a articulação de uma sociedade dos direitos humanos, de valores solidários, interesse público, configurando um substrato para as distintas práticas dos diversos atores sociais, como movimentos, ONGs ou aparelhos institucionais:

As redes de comunicação se constituem de inúmeras tramas, tecidas de diferentes maneiras e por caminhos múltiplos. Essa intensa e incessante conexão dos atores da rede e na rede se expressa, ainda, em importante dado a ser destacado na maneira do CFEMEA atuar e se articular (BUNN, 2012, p. 77).

Dessa forma, Bunn conclui que o CFEMEA é um mediador e mediatizador de uma rede de movimentos de mulheres, pois gera uma apropriação criativa dos espaços e meios de luta, busca um 'fio condutor' entre as diferentes iniciativas e defende o acesso às tecnologias da informação para os atores sociais ${ }^{5}$ com os quais se relaciona, sendo a Internet o meio para ampliar as ações e articulações da cibermilitância (informação, convocação e articulação) e cibercidadania (processos políticos). Considera a mediação como relações no universo simbólico entre os sujeitos num espaço comum de diálogo onde emissão e recepção têm o mesmo estatuto comunicativo e uma prática dialógica e a mediatização como a ausência desse espaço comum e a emissão e recepção como processo distinto. Essa dinâmica fortalece as políticas da organização, como a Advocacy', e o 'controle social' do Estado, através do acompanhamento e fiscalização das políticas públicas, da própria sociedade e junto ao mercado.

Aponta três dimensões-categorias da atuação em rede e na rede e no cenário de "ação à distância" (BUNN, 2012, p. 97): 1) sociabilidade - relações sociais entendidas como redes sociais com vínculos diretos entre os atores e organizações, com espaços pelos conflitos da

\footnotetext{
${ }^{4}$ Acompanhamento no legislativo, articulação com o movimento de mulheres e democratização da informação.

${ }^{5}$ O CFEMEA se relaciona com o movimento de mulheres de todo o país, ONGs feministas, sindicatos, partidos políticos, associações de bairros, grupos de negras, trabalhadoras rurais e domésticas, núcleos de estudos e pesquisas de universidades, conselhos dos direitos da mulher, parlamentos, órgãos governamentais e redes e fóruns nacionais e internacionais. Assessora a Bancada Feminina de parlamentares e Comissões do Congresso Nacional.

${ }^{6}$ Considerada uma ação de advocacia e defesa pública a partir da relação com a sociedade civil organizada.
} 
ação coletiva; 2) espacialidade - conexões espaciais através de redes técnicas; 3) temporalidades históricas - com significados em termos de processo civilizatório.

Bunn encontrou uma combinação de práticas ativistas tradicionais (ação face à face) e de práticas mediáticas (redes) na articulação da ONG com o movimento de mulheres, estado, partidos políticos e sociedade, trazendo mudanças nos modos de pensar e fazer política. "Na atuação do CFEMEA em rede e na rede há um aprofundamento e amadurecimento das ações e práticas políticas que conduzem a apropriação e reapropriação do lugar do movimento de mulheres na relação sociedade civil e Estado" (BUNN, 2012, p. 126).

Com esse trabalho Bunn se inscreve como uma intelectual importante para o estudo das redes, ao utilizar referências brasileiras e europeias para a reflexão de teorias mediáticas. Afirma a potencialidade da Rede e dos estudos das Redes, tanto do ponto de vista teórico quanto metodológico, que a levam a (re)pensar antigas questões e polêmicas dos estudos dos movimentos sociais a partir do cenário informacional contemporâneo. A autora deixa o desafio de pensar processos sociais na sociedade da informação discutindo novas teorias sobre as práticas de apropriação criativas das novas tecnologias da comunicação e informação em prol de uma sociedade dos direitos humanos, que dependem das escolhas dos homens e mulheres envolvidos no tecido social e nas políticas da vida.

\section{REFERÊNCIAS}

BUNN, Maria Cristina. Rede como lugar de Potência: o CFEMEA e as Práticas Políticas Mediáticas. São Luiz: FAPEMA: 2012, 279p.

BUTLER, Judith. Problemas de Gênero, Feminismo e Subversão da Identidade. Rio de Janeiro: Civilização Brasileira, 2003.

CAIAFA, Janice. Nosso Século XXI. Notas sobre Arte, Técnica e Poderes. Rio de Janeiro: Ed. Relume Dumará, 2001.

CASTELLS, Manuel. A Sociedade em Rede: A Era da Informação - Economia, Sociedade e Cultura. São Paulo: Paz e Terra, Vol. I, 1999. 
GOOGLE. A Evolução da Web. Disponível em: <http://www.evolutionoftheweb.com \#\#/growth/day>. Acesso em 30 jul 2012.

HELLER, Agnes. Los Movimientos Culturales como vehículo de cambio. Revista Letra Internacional, Madri, Invierno, 1987/88.

LÉVY, Pierre. O que é o Virtual?. Rio de Janeiro: Editora 34, 1999.

MORIN, Edgar. O Método I. A Natureza da Natureza. Lisboa, Pub. Europa-América, 1980.

PÉLBART, Peter Pál. A vertigem por um Fio. Políticas da Subjetividade Contemporânea. São Paulo: Ed. Iluminuras, 2000.

O Tempo não Reconciliado. In: Alliez, Erc (org) Gilles Deleuze: Uma Vida Filosófica. São Paulo: Ed. 34, 2000b.

Biopolítica e Biopotência no Coração do Império. In: Lins, Daniel \& Gadelha, Sílvio (orgs) Nietzche e Deleuze: que pode o corpo. Relume Dumará; Fortaleza, CE: Secretaria da Cultura e Desporto, 2002.

Vida Capital. Ensaios de Biopolítica. In: Alliez, Erc (org) Gilles Deleuze: Uma Vida Filosófica. São Paulo: Ed. Iluminuras, 2003.

SCHERER-WARREN, Ilse. Redes de Movimentos Sociais. São Paulo, Ed. Loyola, 1996.

Redes emancipatórias: nas lutas contra a exclusão e por direitos humanos. Curitiba: Editora Appris, 2012.

VIRILIO, Paul. O Espaço Crítico: e as perspectivas do tempo real. Rio de Janeiro, Ed. 34, 1999. 